HUOM! Tämä on alkuperäisen artikkelin rinnakkaistallenne. Rinnakkaistallenne saattaa erota alkuperäisestä sivutukseltaan ja painoasultaan.

Käytä viittauksessa alkuperäistä lähdettä:

M. Drake, R. Kauppinen (2021) DEVELOPING VIRTUAL REALITY-BASED TRAINING MATERIALS IN COLLABORATION WITH HIGHER EDUCATION INSTITUTIONS AND COMPANIES, EDULEARN21 Proceedings, pp. 3423-3429. https://doi.org/10.21125/edulearn.2021.0725

PLEASE NOTE! This in an electronic self-archived version of the original article. This reprint may differ from the original in pagination and typographic detail.

Please cite the original version:

M. Drake, R. Kauppinen (2021) DEVELOPING VIRTUAL REALITY-BASED TRAINING MATERIALS IN COLLABORATION WITH HIGHER EDUCATION INSTITUTIONS AND COMPANIES, EDULEARN21 Proceedings, pp. 3423-3429. https://doi.org/10.21125/edulearn.2021.0725

(c) 2021 IATED. All rights reserved. 


\title{
DEVELOPING VIRTUAL REALITY-BASED TRAINING MATERIALS IN COLLABORATION WITH HIGHER EDUCATION INSTITUTIONS AND COMPANIES
}

\author{
M. Drake, R. Kauppinen \\ Haaga-Helia University of Applied Sciences (FINLAND)
}

\begin{abstract}
In this paper, we discuss the potential of virtual reality $(\mathrm{VR})$ as a tool for workplace training and how companies and higher education institutions can collaboratively develop and produce training materials supported by VR technology. Our objective was to create models according to which such cooperation can be practised. We used examples from two industries—healthcare and hospitality - because these industries are suffering from labour shortages, the EU and especially Finland are facing the challenge of underemployment of immigrants, and these industries offer suitable entry-level positions for immigrants. Although companies would like to hire immigrants, they do not have adequate means to test their competencies, and immigrants would like to show their real competencies rather than just linguistic competence. Using the living lab method, we created a three-step workplace training contentcreation model for the hospitality industry and a four-step model for the healthcare industry in cooperation with companies, immigrant training centres, immigrant associations, and two higher education institutions
\end{abstract}

Keywords: Virtual reality, training material, higher education, health care and hospitality companies, living lab.

\section{INTRODUCTION}

The competencies needed in workplaces are changing at an accelerating rate due to labour market transformations. In the future, there will be a demand for millions of new jobs and wholly new occupations. The number of jobs is set to grow by $51 \%$ on the horizon up to 2025 , which will result in 6.1 million new job opportunities globally. New jobs reflect the adoption of new technologies. Clearly, the future of work will not be about college degrees; it will be about job skills. [1]. College and university degrees were previously the passport to working life. Now, it is predicted that companies will train their workforces themselves with skill- and competence-based education [2].

Meanwhile, virtual reality (VR) is emerging as a technology for teaching, learning, and workplace training. This innovation has elicited research interest in domains as diverse as entertainment, medicine, aviation, engineering, nursing, music, and dance. VR has also been used to develop competence recognition models. Despite the abundance of studies on this technology, most research has focused on education and schools and universities as learning environments, and fewer explorations have concerned the process by which higher education institutions and companies collaboratively design, develop, and create VR-based training materials. It is important to research cooperation between companies and higher education faculty, because companies understand what competencies are needed, and higher education faculty members are able to design learning materials from a learner's perspective.

VR is a promising technology whose use has been studied to some extent in the education arena. VR provides new opportunities to create learning material to educators as well as to the industry. Previous research has identified the benefits of interaction, immersion, and the possibility of enabling deep concentration, especially with the help of a virtual classes (head-mounted display (HMD) or standalone headset). The interactivity and immersion of VR may vary at different levels, and VR offers a realistic and almost like real life experience. In Virtual world people can learn by doing, and learning can be either individual or collaborative. [3] [4]. It has been suggested [5] that VR can support learning because it allows students to actively participate to the learning situation. VR is an immersive experience in which a person is deeply concentrated on their assignments without external distractions and unaware of being in a virtual world. Immersion can thus aid learning by reducing external distractions, increasing problemsolving capability, and improving learning engagement and motivation. It is said that VR learning enhances interpersonal communication. [6-9]. VR is fertile ground for tailoring to different kinds of learning styles [10]. 
What is competence, and how does it differ from skill? Competence can be defined as the knowledge, skills, attitudes, and abilities required for success in the workplace. Competence is a measure of both proven skills and proven knowledge [11]. Competence recognition is generally approached as a learning taxonomy, which is typically based on documents presented by students or other methods for example transfer crediting and demonstrations i.e. RPL [12].

A learning taxonomy entails that learning occurs at different levels. A taxonomy is a hierarchical system; one must master lower levels before proceeding to higher levels. There are three domains or basic types of educational objectives: cognitive objectives, which involve mental processes such as memory recall and analysis; affective objectives, which involve interest, attitudes, and values; and psychomotor objectives, which involve motor skills [13]. The taxonomy of learning objectives is a framework for classifying statements of what it si expect or intend students to learn as a result of the instructions [14]. Motivation is the primary factor that determines whether a student will complete a course or assignment and is highly predictive of course engagement; in turn, engagement is a strong predictor of retention [15].

VR has been used to create competence recognition models aimed at helping immigrants exhibit their competencies and skills despite language barriers [16-17]. However, researchers have yet to discover the full potential of this technology. In particular, more detailed investigations should be directed towards cooperation between companies and end users in the development of VR-based training content.

\section{METHODOLOGY}

Our objective is to determine how companies and higher education institutions can collaboratively develop and produce training materials supported by VR technology and create models according to which such cooperation can be practiced.

Our research questions are as follows:

RQ 1: What are the key competencies needed in the hospitality and healthcare industries, and how can they be defined in collaboration with representatives from these industries?

$R Q$ 2: What kinds of VR-based training materials can facilitate the development of these key competencies?

To create our content development model, we used a user-centric living lab and developed the model in an ecosystem comprising companies from the hospitality and healthcare industries, immigrant associations, two higher education institutions the Helsinki Skill Center and Turku Skill Center, and immigrants. The aim of a living lab is to facilitate innovation, create new services and products, produce prototypes, and test creations in cooperation with end users [19-21].

Living labs can be used in various situations, such as when users change their roles from passive consumers to active prosumers, to innovate and involve people in solutions to everyday problems with companies and other stakeholders. The following are different types of living labs:

a) Research living labs that focus on the innovation process

b) Corporate living labs that focus on innovations co-created with stakeholders

c) Organisational living labs where organisation members innovate

d) Intermediary living labs in which various stakeholders innovate in cooperation in a neutral area

e) Time-limited living labs that close when the project ends [22].

Our living lab most closely resembles an intermediary living lab, as a number of different entities were involved in the development process.

The purpose of a living lab is to solve everyday problems and boost the economy via practice-based innovation, rapid development, and testing by users [19]. In our case, the aim was to use our living lab to develop VR learning content for the participating companies.

The healthcare industry was chosen because it is experiencing a persistent shortage of workers especially in Finland and is projected to grow significantly in the coming years. It belongs to a group of emerging occupations, i.e. those that have experienced the most growth over the previous five years. The health care economy is projected to grow by 17 per cent in the next five years [2]. Our healthcare industry partner company is among the largest in Finland; it is over 111 years old and employs more than 20,000 people [23]. Our hospitality industry partners consist of several restaurants in the Helsinki area. 
To create the domain-specific content development model, we conducted several workshops with companies about learning objectives and the key competencies needed in their respective industries. We went through the curriculums of the degrees in the field and selected the most desirable competencies. A curriculum is a framework of student expectations and experiences that students meet in the educational process. [23]. It is a purposeful plan for many possible learning activities and desired goals [23].

Several taxonomies describe levels of learning and knowledge. Bloom's taxonomy is widely used and defines three domains of learning: cognitive, affective, and psychomotor skills. Marzano's new taxonomy focuses more on cognitive abilities and has three main systems: the self, metacognitive, and cognitive systems [24-25]. Our content model is based on both Bloom's and Marzano's taxonomies.

When creating content for virtual reality, it is also important to acknowledge its limitations. For example, Oculus's instruction manual discourages the use of VR for more than 30 minutes at a time [26].

The training material was tested in collaboration with immigrant associations and immigrants at Helsinki Skill Centre and Turku Skill Centre.

In addition, we interviewed 63 immigrants with different backgrounds about their needs and employment goals.

\section{RESULTS}

As a result, of our living lab work, we created a three-step content model for the hospitality industry and a four-step equivalent for the healthcare industry [17]. The levels for the hospitality industry model are knowledge, comprehension, and application. Level 1 means that the learner is able to identify health code violations in the restaurant environment; level 2 the learner is able to answer simple questions related to hygiene in the restaurant environment and Level 3 the learner is able to handle food products according to hygienic standards in the restaurant environment. [16-17].

For the healthcare industry model, they are cognitive (GOG), psychomotor (PSM), affective (AFF), and pair and teamwork (PAW), as well as self-awareness skills. Several competencies correspond to multiple levels, thus providing the model with flexibility and extendibility. Level 1 learner is able to do simple tasks based on general knowledge and skills, Level 2: learner is able to do simple tasks based on basic field-specific knowledge and skills, Level 3: learner is able to do standard tasks based on advanced field-specific knowledge and skills, Level 4:learner is able to do non-standard tasks based on analysing situations and creating solutions to specific problems. In addition, Self-awareness skills, learners can understand and assess their own knowledge and skills and their limits, can explain and justify decisions, can ask for and provide feedback and can recognise and manage their own feelings. [16-17].

While developing our model, we used a competence recognition model that was originally developed as part of a master's thesis as a template [27] for modelling multiple complex competencies and connecting them to VR implementations.

After mapping the key competencies and creating the content models, partner companies selected job tasks for which to create VR training pilot content. After carefully describing the job tasks, we developed a script for the VR content. The script was introduced and evaluated point by point in a workshop for the company representatives. Subsequently, we created VR training content for each step using the Unity game engine and 360 videos before evaluating the content with the participating companies and immigrant groups.

The VR content was created in both Finnish and English and included learning materials and tests. Safety training is a field in which VR is relevant [28], and the safety of the working environment is important in both the hospitality and healthcare industries. Therefore, we created training material called 'Spot the Problem', the purposes of which was to find grievances in the working environment and observe, for example, patients' mental states.

Figure 1 is an example of how the original script for 'Spot the Problem' was created for the 360 video. The training material Spot the Problem in care industry in Figure 1 was created for Level 1 and it partially covers Level 2. For content testing, we used Oculus Quest virtual glasses (standalone headset), as they were easy to carry to different testing sites. We also created instructions on how to use the standalone headset and touch control. Users could choose to practice or take tests that evaluate their understanding of the content. 

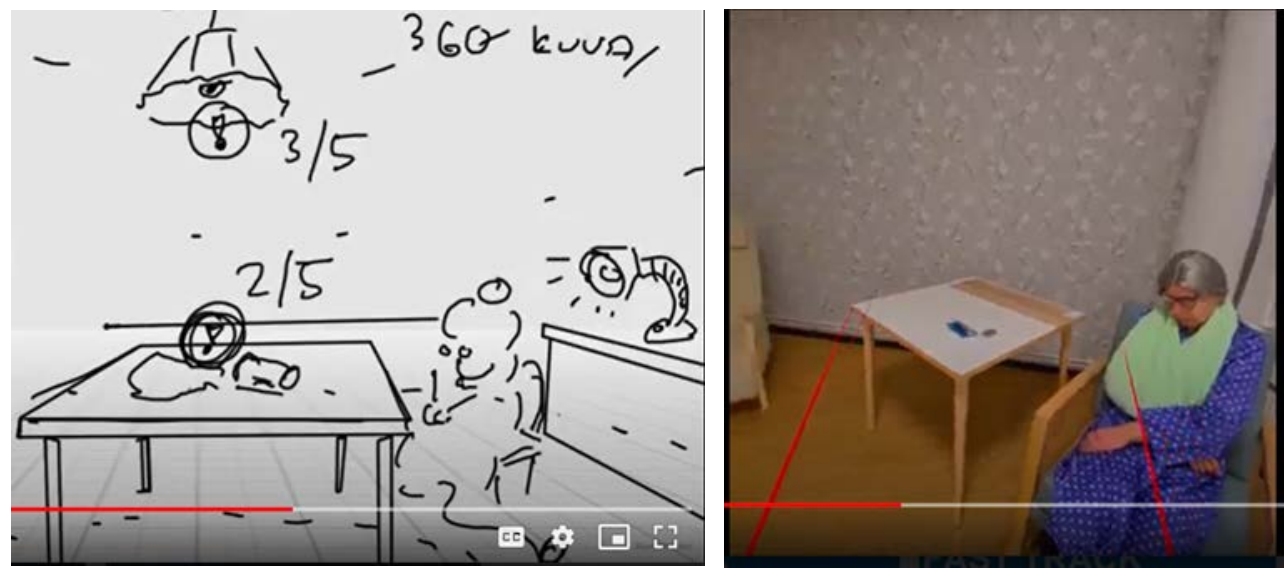

Figure 1. From transcript to 360 video.

We tested to some extent, the virtual hygiene passport test, training material Level 2 for hospitality industry. Finnish hygiene author Ruokavirasto requires hygiene passport and passing the test is required of all persons who work with easily perishable food items, for example, in restaurants. Normally, the test is done on paper by responding to 40 claims right or wrong. [29]. We created the test using virtual technology and organised both virtual and official paper test and evaluated which test was easier to pass. Although testers got good results from the Virtual Test, only one in nine testers passed the test. The main reason why they did not pass the test was that they did not understand the substance of the question.

Our initial objective was to understand how companies and higher education institutions can collaboratively develop and produce training materials supported by VR technology. Our objective was to create models according to which such cooperation can be practiced. Figure 2 illustrates our cooperation model. Firstly, we studied the curriculum of the chosen occupations in the hospitality and health care industry. We created a list of the most needed competencies. After that, we had several workshops with the companies to define key competencies. As a result, of the workshops, the threelevel and four-level content models were created and evaluated in co-operation with the companies. For the training content creation, different scripts were developed that went through with the companies. The content was created at all levels of the content model. In addition, the content was tested with the immigrant groups. On top of everything else, some health care and hospitality teachers evaluated the training content stating that it can also be used in an educational institution setting in addition to on the workplace training.

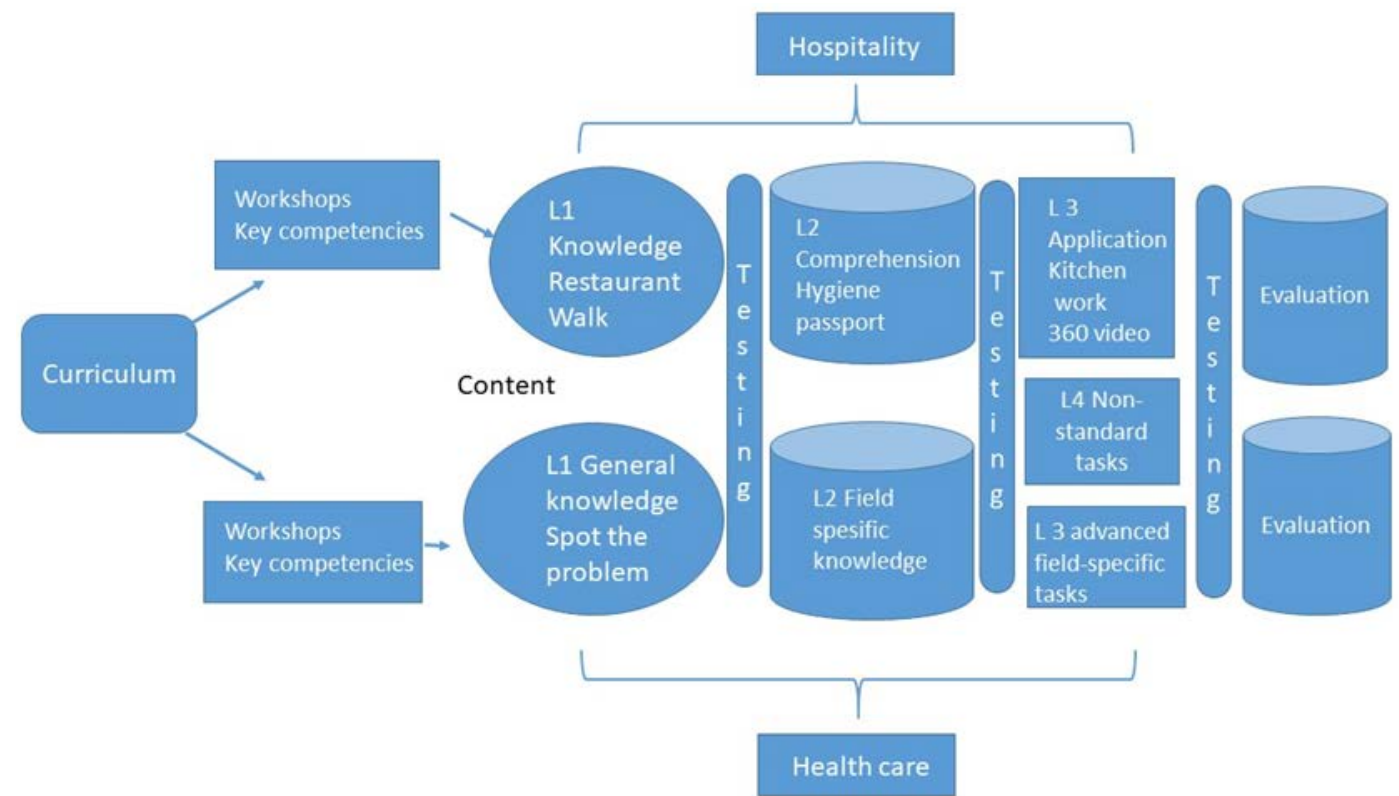

Figure 2. illustrates the training content co-creation model in the Living Lab. 


\section{CONCLUSIONS}

The Living Lab model was effective in helping us reach our objective. We managed to reach relevant stakeholders, and the companies and Immigrant Association as well as the Helsinki Skill Centre and Turku Skill Centre were active participants in the living lab ecosystem. Several workshops and testing rounds were needed before the training material could be created, tested, and evaluated. The taxonomies and three-level model for the hospitality industry and four-level model for the healthcare industry helped participants in the Living Lab ecosystem map the key competencies and desired learning materials. The immigrant groups provided excellent feedback on both the content and the challenges of using virtual glasses.

Identifying key competencies (RQ1) was the most demanding and time-consuming task. It was difficult to find mutually convenient times at which to evaluate the content model and define key competencies with the companies. Restrictions imposed as a result of the COVID-19 pandemic also slowed down the process to some extent, as they made it difficult to find places to shoot videos and test groups, and the hospitality industry was almost entirely shut down.

What comes to our RQ2 RQ 2: What kinds of VR-based training materials can facilitate the development of these key competencies? The content model with different levels helped to ideate the training content together with the companies. Content was produced for each level of the model using simple examples to quickly access educational materials to be tested on immigrants. Different kinds of material for each level motivated our testing groups - some of the testers considered the contents and various tests even a fun way to learn. In Immigrants viewpoint, good in content was multisensory, the same topic was presented in images, text and sounds.

How did companies experience cooperation in the co-development of training materials? In the beginning, it was clear that the companies did not realise the potential of VR. After the first workshop, the representatives were somewhat sceptical about the viability of using VR for workplace training.

Their attitudes changed dramatically after testing the first training materials. They were impressed with the intensity and immersion they provided, and they expressed hope for the inclusion of more test materials and test questions. They also provided some suggestions for future development. From the perspective of these companies, VR technology can be used for the orientation of new workers and the recapitulation of learned competencies.

Our next step is to develop the content development model to include, alongside VR technology, the possibilities of augmented reality in human resources training and in new workers' orientation. Although we tested to some extent, the differences between the VR test and the test on paper, further testing needs to be done to evaluate what kind of testing is suitable for testing immigrant with poor language skills.

\section{ACKNOWLEDGEMENTS}

This project was funded by the European Social Fund.

\section{REFERENCES}

[1] R. Kumar and S. George, Why skills - not degrees - will shape the future of work, The Job Reset Summit. World Economic Forum, 2020.

[2] World Economic Forum, "Jobs of Tomorrow: Mapping Opportunity in the New Economy," World Economic Forum, 2020. Retrieved from https://www.weforum.org/reports/jobs-of-tomorrowmapping-opportunity-in-the-new-economy-

[3] B. Dalgarno, J. Hedberg, and B. Harper, "The contribution of 3D environments to conceptual understanding," in Proceedings from the 19th Annual Conference of the Australasian Society for Computers in Learning in Tertiary Education, 2002. ASCILITE 2002. vol. 1, pp. 149-158, 2002.

[4] A. Kulik, A. Kunert, S. Beck, and B. Frölich, "Collaborative Virtual Reality for Joint Learning Experiences," in Proceedings from the 12th International Conference on Computer Supported Collaborative Learning, 2017. CSCL 2017. vol. 1, pp. 721-722, 2017.

[5] M. Melo, E. Bentley, K. McAllister, and J. Cortez, "Pedagogy of Productive Failure: Navigating the Challenges of Integrating VR into the Classroom," Journal of Virtual Worlds Research, vol. 12, no. 1, pp. 1-21, 2019. 
[6] M. P. Wallach, R. Safir, E. Horef, E. Huber, and T. Heiman, "Presence in Virtual Reality. Importance and Methods to Increase It," Virtual Reality, March, 2012.

[7] D. Ota, B. Loftin, T. Saito, R. Lea, and J. Keller, "Virtual Reality in Surgical Education," Computers in Biology and Medicine, vol. 25, no. 2, pp. 127-137, 1995.

[8] T. Parisi, Learning Virtual Reality: Developing Immersive Experiences and Applications for Desktop, Web, and Mobile. O'Reilly, 2015.

[9] L. Zheng, T. Xie, and G. Liu, "Affordance of Virtual Reality for Collaborative Learning," in International Joint Conference on Information, Media and Engineering, 2018. ICIME 2018. vol. 1, pp. 6-10, 2018.

[10] H-M. Huang, U. Rauch, and S-S. Liaw. "Investigating Learners' Attitudes Toward Virtual Reality Learning Environments: Based on a Constructivist Approach," Computers and Education, vol. 55, no. 3, pp. 1171-1182, 2010.

[11] P. Hager and A. Gongzi, "What is Competence?” Medical Teacher, vol. 18, no. 1, pp. 15-18,1996.

[12] Finnish National Agency for Education and Ministry of Education and Culture, Report on the Referencing of the Finnish National Qualifications Framework to the European Qualifications Framework and the Framework for Qualifications of the European Higher Education Area. Finnish National Agency for Education, 2018.

[13] G. O'Neill and F. Murphy, "Guide to Taxonomy and Learning," UCD Teaching and Learning, 2010. Retrieved from https://www.ucd.ie/t4cms/ucdtla0034.pdf

[14] D. R. Krathwohl, "A Revision of Bloom's Taxonomy: An Overview," Theory Into Practice, vol. 41, no. 4, pp. 212-218, 2012. DOI: 10.1207/s15430421tip4104_2

[15] R. Ryan and E. Deci, "Self-determination theory and the facilitation of intrinsic motivations, social development, and well-being," American Psychologist, vol. 55, 68-78, 2000. doi: 10.1037110003066X.55.1.68R

[16] R. Kauppinen and M. Drake, "Virtual Reality in Competence Recognition for Immigrants," in Proceedings from the 14th International Technology, Education and Development Conference, 2020. INTED 2020. vol 1, pp. 5578-5582, 2020.

[17] R. Kauppinen, M. Drake, K. Anttila, and E. Lindgren, Implementing Virtual Reality Based Competence Recognition. IEEE 2021 Proceedings 19th International Conference on Information and Education Technology ICIET 2021.

[18] M. Pallot, B. Trousse, B. Senach, and D. Scapin, "Living Lab Research Landscape: From UserCentered Design and User Experience towards User Cocreation," First European Summer School 'Living Labs', 2010. Retrieved from https://hal.inria.fr/inria-00612632

[19] M. Westerlund and S. Leminen, "Managing the challenges of becoming an open innovation company: experiences from living labs," Technology Innovation Management Review, October, pp. 19-25, 2011.

[20] H. W. Chesbrough. Open Innovation: The New Imperative for Creating and Profiting from Technology. Boston: Harvard Business School Press, 2003.

[21] A. Ståhlbröst and M. Holst, The Living Lab Methodology Handbook. 2021.

[22] Mehiläinen yrityksenä, 2021. Retrieved from https://www.mehilainen.fi/yritysinfo/mehilainen-yrityksena

[23] J. Wiles, Leading Curriculum Development. UK: Sage, 2009.

[24] W. Lorin and D. Krathwohl (eds.), A Taxonomy for Learning, Teaching, and Assessing: A Revision of Bloom's Taxonomy of Educational Objectives. New York: Longman, 2001.

[25] R. J. Marzano and J. S. Kendall, The new taxonomy of educational objectives, 2 nd ed. Thousand Oaks, CA: Corwin Press, 2007.

[26] Oculus, "Health and safety warnings," 2020. Retrieved from https://www.oculus.com/legal/healthand-safety-warnings/

[27] K. Anttila and E. Lindgren, "Virtual reality-assisted competence recognition - supporting the employment of immigrants to the care industry," Master's Thesis, Haaga-Helia University of Applied Science, 2020. 
[28] G.Makransky, S. Borre-Gude, and R. Mayer, "Motivational and cognitive benefits of training in immersive virtual reality based on multiple assessments," Journal of Computer Assisting Learning, vol. 35, pp. 691-707, 2019.

[29] Ruokavirasto.fi/hygieniapassi, 2021. Retrieved

https://www.ruokavirasto.fi/henkiloasiakkaat/hygieniapassi/ 